\title{
A ANTROPOLOGIA EM FRIEDRICH NIETZSCHE
}

\author{
Prof. Dr. Alberto Vivar Flores \\ DOI: $\quad 10.20399 / P 1982-999 X .2015 v 1 n 2 p p 61-71$
}

\begin{abstract}
Resumo: O texto Intitulado "A Antropologia em Friedrich Nietzsche", se propõe abordar o conceito de "Super-homem" que, junto com o de "Vontade de Poder", "Niilismo", "Eterno Retorno do Mesmo" e o de "Justiça," constitui os termos fundamentais da metafísica de Nietzsche, segundo Martin Heidegger. Acredita-se, portanto, que é preciso ter em conta todo o contexto metafísico no qual são colocados ditos termos para entendê-los. Ao fazer uma abordagem antropológica a partir da filosofia de Nietzsche, não pensamos estar cometendo uma heresia em relação a Friedrich Nietzsche (1844-1900), toda vez que, ademais de acreditar que o pensamento nietzschiano permite uma abordagem antropológica, já contamos com o exemplo de Max Scheler (1874-1928), o qual, na sua obra "Mensch und Geschichte", expressavase assim a respeito do "Super-homem".
\end{abstract}

\section{Introdução}

Com o título "A Antropologia em Friedrich Nietzsche", nos propomos abordar o conceito de "Super-homem" que, junto com o de "Vontade de Poder", o de "Niilismo", o de "Eterno Retorno do Mesmo" e o de "Justiça",constitui os termos fundamentais da metafísica de Nietzsche, segundo Martin Heidegger. Sobra dizer, portanto, que é preciso ter em conta todo o contexto metafísico no qual são colocados ditos termos para entender este.

Ao fazer uma abordagem antropológica a partir da filosofia de Nietzsche, não pensamos estar cometendo uma heresia em relação a Friedrich Nietzsche (1844-1900), toda vez que, ademais de acreditar que o pensamento nietzschiano permite uma abordagem antropológica, já contamos com o exemplo de Max Scheler (1874-1928), o qual, na sua obra "Mensch und Geschichte", expressava-se assim a respeito do "Superhomem":

[...] figura do 'super-homem', do único responsável, pronto para assumir gozoso toda responsabilidade, do criador, do que dá sentido à Terra, do único que legitima quanto chamamos de humanidade e povo, história e acontecer cósmico; ainda mais, do ápice mesmo e suprema cume onde rematar o ser (SCHELER, 1981, pp.69-70)

Por outra parte, pelos estudos feitos até agora, sabemos que o conceito de "Super-homem", como afirma Bernhard Welte (1981, p. 67), "resume e indica algo que está 'acima' do homem e assim mesmo faz parte do homem”. Portanto, o conceito 
mesmo de "Super-homem" abre já possibilidades para uma abordagem segundo nossas intenções.

Vamos, pois, a decifrar o tema central de "Also sprach Zarathustra" (1984).

\section{A origem do termo}

Segundo Ferrater Mora (1986, p. 3170), seguindo os passos da pesquisa de Walter A. Kaufmann, Nietzsche não teria sido o criador do termo, uma vez que "pode encontrar-se 'hyperantropos' nos escritos de Luciano, no século II d.C.”.

Mas, embora ele não tenha sido o autor original, sem dúvida, foi ele quem fez famosa tal expressão, traduzindo-a por "Übermensch".

OlgáriaChaimFerez e Marilena de Souza Chauí coincidem em afirmar que, para o vocábulo "Übermensch", "não há equivalente adequado em português" (OS PENSADORES, 1983, p.. 228); porém indicam que o $§ 4$ do "Assim falou Zaratustra" “dá o contexto e a direção em que deve ser lida a palavra - 'travessia', 'passar', 'atravessar'",1

De resto, também nos dizem que 'todos estes jogos com 'Über' (sobre, por sobre, para além) são demarcatórios quanto ao sentido do prefixo em 'Übermensch", (OS PENSADORES, 1983, p.. 228). Assim sendo, "Übermensch" deve ser traduzido por "além do homem".

Nós, apesar de estarmos conscientes desta declaração, vamos continuar empregando, ao longo do nosso trabalho, o termo "Super-homem", entendido como o equivalente ao "além do homem", com o fim de facilitar a exposição de nosso tema.

Por conseguinte, filosoficamente falando, o que quer dizer a cifra do "Superhomem"?

\section{Limpando o caminho: As falsas interpretações}

Talvez tenham sido os limites da própria linguagem a causa de que a filosofia de Nietzsche, ou melhor, o próprio Nietzsche tenha sido tão mal compreendido. Conceitos tão importantes como "Der Wille zur Macht" e "Übermensch", já durante a vida do

\footnotetext{
${ }^{1}$ Cf. OS PENSADORES, p. 228: Introdução, § IV: “O homem é corda distendida entre o animal e o Superhomem, uma corda sobre um abismo: travessia perigosa, temerário caminhar, perigoso olhar para trás, perigoso tremer e parar. A grandeza do homem é ser ele uma ponte, e não uma meta; o que se pode amar no homem é ser ele uma passagem e um termo" (NIETZSCHE, Friedrich. Assim falava Zaratustra, São Paulo: Hemus Editora, 1979, p. 11).
} 
próprio Nietzsche, mas, sobretudo, depois da sua morte, sofreram as maiores incompreensões.

É-nos dito que "a principal responsável por essa deformação foi sua irmã Elizabeth, que, ao assegurar a difusão de seu pensamento, organizando o NietzscheArchiv, em Weimar, tentou colocá-lo a serviço do nacional-socialismo" (OS PENSADORES, 1983, p.. XV)

Seja disso o que for, nós vamos, num primeiro momento, a colocar aquilo que, segundo nossa interpretação, o conceito que nos ocupa "não" tem em Nietzsche; para, num segundo momento, fazer o esforço de atingir o seu sentido específico.

De início, Nietzsche "não" entende por "Übermensch" o "grande homem", enquanto personalidade historicamente célebre; nem o "homem biologicamente superior", enquanto descendente evolutivo do homem; tampouco, o "herói", o "santo" ou o "gênio", enquanto indivíduo que se julga acima da normalidade ou cotidianidade humana pelo poder de seu pensamento, pela força de sua vontade.

Nesse sentido, discordamos de todas as interpretações feitas ao estilo de, por exemplo, Enrique Dussel (1980, p. 14), quando diz: "O que é Nietzsche senão uma apologia do homem conquistador e guerreiro?". O mesmo dizemos para aquelas interpretações que querem definir o "Super-homem" em relação direta com a "morte de Deus”, pois, para elas, “a cifra do 'Super-homem' aparece exatamente onde acontece a morte de Deus. Ocupa o lugar onde Deus foi destronado" (WELTE, 1981, p. 69). Isto seria como investi-lo de um caráter divino, no sentido mais tradicional.

Mas se discordamos de tantas interpretações prevalentes até agora, então, qual é, para nós, o sentido específico do termo "Übermensch"?

\section{3. "Übermensch": um conceito filosófico}

Limpo das grosseiras interpretações biológicas, políticas, militares, místicas e até religiosas, vamos estudar o "Übermensch" conduzidos pela meditação de M. Heidegger (1889-1976), o qual, segundo Giorgio Penzo (1981, p. 23), sustenta que Nietzsche "permanece sempre no âmbito da representação metafísica, embora apreenda o Ser não mais na dimensão platônica cristã, mas em um horizonte de valores opostos. Noutros termos, no fundo, o Ser é entendido sempre em sentido ôntico, embora visto como ente supremo" 
Para tornar mais didática nossa exposição, vamos subdividir o presente enunciado em diversos parágrafos.

\subsection{Nietzsche, Zaratustra ou o "Super-homem"}

O conceito de "Super-homem, que aparece timidamente em "Aurora" (18801881), depois mais nítido em "Gaia Ciência” (1881-1882), torna-se fulgurante em "Assim falou Zaratustra" (1884). A tal grau isto é assim, e Nietzsche o experimenta, que poderíamos dizer que os termos são, em certa medida, intercambiáveis: "Zaratustra, ou o 'Super-homem' que nele fala" (WELTE, 1981, p. 68). "Ou melhor, Nietzsche e Zaratustra se convertem em uma mesma pessoa" (Penzo, 1981, p. 17).

Isto porque, Nietzsche, coerente com seu pensamento, foi o único, até agora, que assumiu a transfiguração provocada na humanidade pela mutação do Ser operada pelo "Niilismo":

Quem aqui toma agora a palavra não tem feito, até o presente, mais que refletir; como filósofo e anacoreta, por instinto, que encontra maior vantagem vivendo apartado, à margem, na paciência, na demora e por trás, como um espírito pesquisador e atrevido, o qual já se tem extraviado mais de uma vez em todos os labirintos do futuro, como um pássaro espectral e profético que olha para trás quando relata o que virá, primeiro niilista perfeito da Europa, mas que já tem superado o niilismo que morava na sua alma, vivendo-o até o fim, deixando-o atrás de si, por baixo de si, fora de si (NIETZSCHE, 1986, pp. 29-30).

Ao respeito, confirmando o modo antropológico de ser de Nietzsche, nos disse Ciro Mioranza ([s.d.], pp. 11-12)

Nietzsche era dotado de um espírito irrequieto, perquiridor, próprio de um grande pensador. De índole romântica, poeta por natureza, levado pela imaginação, Nietzsche era o tipo de homem que vivia recurvado sobre si mesmo. Emotivo e fascinado por tudo o que resplende vida, era ao mesmo tempo sedento por liberdade espiritual e intelectual; levado pelo instinto ao mundo irreal, ao mesmo tempo era apegado ao mundo concreto e real; religioso por natureza e por formação, era ao mesmo tempo um demolidor de religiões; entusiasta defensor da beleza da vida, era também crítico feroz de toda fraqueza humana; conhecedor de si mesmo era seu próprio algoz; seu espírito era campo aberto em que irromperam as mais variadas tendências, sob a influência de sua agitada consciência. Espírito irrequieto e insatisfeito, consciência eruptiva e crítica, vivia uma vida de lutas contra si mesmo, de choques com a humanidade, de paradoxos sem limite. Assim era Nietzsche. 
A partir do Homem Nietzsche, pois, o 'Ser'

já não é a perfeição imutável e serena, idêntica consigo mesma, essa realidade acabada, simples e transparente que a razão humana pode penetrar até os seus últimos limites. O Ser é agora 'Vontade de Poder' [...] O Ser é, então, enquanto 'Vontade de Poder', um perpétuo devir, uma pluralidade sempre cambiante que oferece infinitas possibilidades de ser decifrada (CASTRILLO, 1986, p. 17).

Nietzsche, portanto, não fez outra coisa que assumir-se e viver no contexto do Ser, entendido como "Vontade de Poder". E se o "Eterno Retorno do Mesmo" expressa a maneira como o ente, na sua totalidade, é a existentia do ente, então, o Ser Humano Nietzsche caracteriza aquela "humanidade" que é requerida para essa realidade, enquanto tal, na sua totalidade.

\subsection{O "Super-Homem": uma rebeldia metafísica}

Ora, por outra parte, se é verdade o que Heidegger (1971, p. 234) diz: que "a verdade sobre o ente enquanto tal na sua totalidade é, em cada momento, assumida, estruturada e preservada por uma 'humanidade"', então, devemos perguntar-nos: qual é essa "humanidade" na vida, na obra e no pensamento nietzschiano?

Sem lugar a dúvida, é a "humanidade" chamada de "Super-homem", pois, dela, ele mesmo diz: "O homem que, no meio do ente, se comporta em relação ao ente - (o qual ente, enquanto tal, é 'Vontade de Poder' e, na sua totalidade, 'Eterno Retorno do Mesmo') - se chama 'Super-homem’” (HEIDEGGER, 1971, p. 234). E explica:

O 'Super', no nome do 'Super-homem', contém uma negação e significa o fato de ir 'para além do homem', tal qual ele tem sido até agora. O 'não' desta negação é incondicional, absoluto, enquanto procede do 'sim' à 'Vontade de Poder' e enquanto ele visa diretamente à interpretação platônica, cristã e moral em todas suas formas derivadas, manifestas ou ocultas. A afirmação negativa decide, metafisicamente, a conversão da história da humanidade numa nova história (HEIDEGGER, 1971, pp. 234235).

Tal história não é outra senão a construída a partir do horizonte do "Super-homem".

O "Super-homem, pois, inicialmente, é uma "Vontade de Poder" negativa, rebelde contra o status quo imperante, metafísico: “O 'Super-homem' está, propriamente, concentrado numa vontade, a absoluta negação da essência até agora 
prevalente do homem" (HEIDEGGER, 1971, p. 235), isto é, aquela que concentra o Ser do ente humano na definição de "Homo Sapiens", quer dizer, na "Razão". Porém, esta negação niilista da "Razão" não a exclui, senão que

a coloca ao serviço da animalitas. Ora, a noção de 'animalidade' é, previamente, invertida. Ela não equivale mais à sensualidade, nem simplesmente àquilo que tem de inferior, de vil no homem. A 'animalidade' é o corpo 'corporante', isto é, cheio de seus impulsos próprios e impondo a todas as coisas o seu élan impulsivo. Este nome designa a marcante unidade dominadora que constitui todos os impulsos, todos os ardores, todas as paixões que querem a vida mesma. Pelo fato de que a 'animalidade' vive de modo 'corporal', ela é tudo segundo o modo da 'Vontade de Poder'. Portanto, esta 'Vontade' constitui o caráter fundamental de todo ente, e é somente a 'animalidade' o que determina ao homem a ser um ente verdadeiro [...] Todas as faculdades do homem são, metafisicamente, predeterminadas enquanto modalidades que o 'Poder' se dispôs a exercer (HEIDEGGER, 1971, p. 236).

Por outras palavras, é o pleno exercício do que denominamos de "Natureza humana", "Animal humano", "Ser humano", "Realidade Humana" ou "Ente ônticoontológico".

A respeito, o próprio Nietzsche dirá: "Tudo é corpo e nada mais; a alma é simplesmente o nome de qualquer coisa do corpo" (NIETZSCHE, 1979, p. 26).

\subsection{Um acontecimento historial: a revolução metafísica}

Aqui localizamos, pois, o ponto de partida da conversão da história da humanidade para uma nova história, uma vez que a essência do homem prevalecente até agora, "a racionalidade, se encontra transposta na 'animalidade', no sentido da corporante "Vontade de Poder'” (HEIDEGGER, 1971, p. 236). A ruptura radical entre um "antes" e um "depois" histórico aparece no momento em que a "Negação" convertese em "Afirmação", já que

Este é o ponto decisivo da 'filosofia dionisíaca': o instante supremo em que a negação se nega a si mesma, como poder autônomo, e se transmuta em afirmação da vida. $\mathrm{O}$ negativo não desaparece, senão que se converte em um poder ao serviço da afirmação, essa cara oculta, até agora, de nossa 'Vontade de Poder', que constitui, no entanto, sua essência mais própria. Da afirmação derivarão os novos valores desconhecidos até agora (CASTRILLO, 1986, p. 16). 
Quer dizer, as perspectivas de uma nova história construída, desta vez, no horizonte traçado pelo "Super-homem".

Este acontecimento só é possível de ser valorizado, se temos suficientemente em conta o peso metafísico que significou o definir a essência do homem no sentido da 'racionalidade', ou melhor, desde a subjetividade incondicional da 'Razão'. Aqui, tem lugar, pois, um acontecimento epocal, isto é, a batalha entre duas concepções metafísicas: aquela que define o ser do ente enquanto 'Razão' (subjetividade incondicional da racionalidade) e aquela que o entende como "Vontade de Poder" (subjetividade incondicional do querer).

Pela inversão niilista da primacia do ato de representar em primacia do querer, enquanto 'Vontade de Poder', a 'Vontade' chega à soberania incondicional na essência da subjetividade [...] A 'Vontade' é, de hoje em diante, pura autolegislação: o comando tendendo para sua essência, isto é, o comandar, puro exercício do Poder"'(HEIDEGGER, 1971, p. 241)

Com esta inversão, portanto, teríamos o surgimento do "Super-homem", enquanto "Subjetividade incondicional da 'Vontade de Poder"”

Pela inversão da subjetividade do incondicionado ato de representar em subjetividade da 'Vontade de Poder' cai a primacia da 'Razão' como via de acesso e instância orientadora para o projeto do ente. A subjetividade acabada da 'Vontade de Poder' é a origem metafísica da necessidade de essência do 'Super-homem' (HEIDEGGER, 1971, p. 242)

Desde logo, aqui não se trata de uma mera revolução científica, tecnológica ou social, mas de uma revolução de raiz metafísica que provoca toda uma revolução cultural. Ou, como o próprio Heidegger nos diz, num texto paradigmático:

De hoje em diante, porque ele é só (a) 'Vontade' que representa e que institui valores para o ser do ente, enquanto tal na sua totalidade, é preciso que o homem ofereça à subjetividade acabada os laços de sua pura essência. Porque a 'Vontade de Poder', enquanto subjetividade acabada, não pode legitimar sua essência em outros lugares que no sujeito, enquanto que tal homem é, marcadamente, o homem que está 'para além' de todos os homens até agora. De tal modo que, posta no seu grau supremo, a 'Vontade de Poder', enquanto subjetividade acabada, é o supremo e o único sujeito, isto é, o 'Super-homem'. Ele ultrapassa, não só de modo niilista ao ser humano que prevaleceu até agora, senão também enquanto inversão desse ser para além dele mesmo na sua incondicionalidade, quer dizer, de início: que a integralidade do ente seja o 'Eterno Retorno do 
Mesmo'. A nova humanidade, no meio do ente, o qual na sua totalidade é sem finalidade e, enquanto tal, 'Vontade de Poder', deve necessariamente querer o 'Super-homem', supondo-se que ela se queira a si mesma e, segundo sua maneira própria de ser, ela queira um fim. (HEIDEGGER, 1971, p. 243)

Um "fim" desejado e arraigado na "razão" e na "vontade" de movimento natural, vital e espontâneo da própria "imanência" do ente. Assim, Heidegger (1971, pp. 243244) conclui de modo lapidário: “O 'Super-homem' vive pelo fato de que a nova humanidade quer o ser do ente como 'Vontade de Poder'. Ela quer este ser porque ela mesma é um tender para este ser, isto é, se quer enquanto humanidade incondicionalmente abandonada a ela mesma".

É neste contexto que adquirem significado as palavras com as quais Nietzsche conclui a Primeira Parte do "Assim Falou Zaratustra": "Todos os deuses morreram, agora queremos que viva o 'Super-homem'! Seja esta, chegado o grande meio-dia, nossa última vontade!". Conclusão que, pela sua vez, esclarece as palavras da Introdução: “O 'Super-homem' é o sentido da Terra. Que vossa vontade diga: seja o 'Super-homem’ o sentido da Terra” (§ 3).

\subsection{Para uma nova história: uma nova humanidade}

Ora, esta subjetividade incondicional da 'Vontade de Poder', enquanto nova fundamentação da realidade, exige uma nova "humanização" de tal realidade. Nova "humanização" que implica, tanto a queda da realidade fundamentada na subjetividade incondicional da "Razão" ("Queremos uma concepção antimetafísica e artística do mundo", Vontade de Poder, Livro IV, § 1041), como a queda da "realidade humana" prevalente até agora ("A força e o poder dos sentidos constitui um fundamento essencial do homem bem formado e completo; ante tudo, deve formar-se o magnífico 'animal', que importa toda 'humanização’!”, Vontade de Poder, Livro IV, § 1038).

Por outras palavras, a nova "humanização" se postula como uma “desumanização" radical do mundo e do homem prevalentes até agora.

O niilismo é, então, a consciência de um longo desperdício de forças, a tortura do 'em vão', a insegurança, a falta de oportunidade para refazer-se de alguma maneira, de tranquilizarse ainda com qualquer coisa; a vergonha de si mesmo, como se um se tivesse mentido a si mesmo demasiado tempo (Vontade de Poder, Livro I, $\S 12$ A) 
Por suposto, esse movimento de "humanização"/"desumanização" - que poderíamos caracterizar como um "movimento dialético (com perdão de Nietzsche) -, naturalmente, exige uma "síntese", quer dizer, uma "outra" "humanização" como conteúdo de uma "nova história".

É preciso, pois, que o mundo se "humanize" a partir do "além-do-homem" ("Sempre que se fala de 'humanizar' o mundo, equivale a dizer apropriar-se do mundo", Vontade de Poder, Livro III, § 606). Trata-se, portanto, de realizar a passagem do "homem" ao "Super-homem". "A passagem para o 'Super-homem' transforma essencialmente, ao 'homem', tal qual tem sido até agora, no estado do homem “invertido"” (HEIDEGGER, 1971, p. 246).

O que quer dizer isso? Quer dizer que o homem se assuma, com todas as consequências, a partir da subjetividade incondicional da "Vontade de Poder". Porque "se o ente, enquanto 'Vontade de Poder', rainha na totalidade do 'Eterno Retorno do Mesmo', é preciso que a subjetividade incondicionada e acabada da 'Vontade de Poder' se determine humanamente na subjetividade do 'Super-homem"' (HEIDEGGER, 1971, pp. 250-251), já que a verdade do ente enquanto tal (Vontade de Poder) na sua totalidade (Eterno Retorno do Mesmo) é assumida, estruturada e preservada por uma "humanidade", neste caso, a do "Super-homem".

Ora, “a partir do momento em que a 'animalidade' do homem é conduzida até a 'Vontade de Poder', como essência própria desta 'animalidade', o homem se transforma, finalmente, no 'animal firmemente estabelecido"” (HEIDEGGER, 1971, p. 245). Quer dizer, no sujeito e no objeto supremo dessa nova história.

Isto porque, desde o ponto de vista niilista, 'humanização' significa fazer do homem, já agora, o homem da inversão da primacia da 'Razão' na primacia do 'corpo'. Tudo o qual quer dizer, portanto: interpretar o ente, enquanto tal na sua totalidade, segundo este homem 'invertido'” (HEIDEGGER, 1971, p. 246).

Assim, a Antropologia Filosófica proposta por Nietzsche se realiza, pois "o fato de que se imprima ao devir o caráter de Ser, supõe a mais alta 'Vontade de Poder'" (Vontade de Poder, Livro III, § 609).

\section{Conclusão}


Chegados até aqui, não nos resta mais que reconhecer o caráter nitidamente metafísico do conceito de "Super-homem". Conceito que, francamente, continuamos a indagar, apesar de ter obtido algumas conclusões: o "Super-homem" desconhece esperanças supra terrenas; também não conhece preceitos e leis preestabelecidas que deve seguir; consequentemente, o "Super-homem" vive "além do bem e do mal"; o "Super-homem" possui um vigor interior devindo do seu próprio ser, uma força de identidade autorrealizadora de seu próprio ser, a qual, tranquila e segura de si mesma, já por nada mais pode ser desviada ou perturbada; o "Super-homem" é um criador, ele está livre de toda divisão, de toda cisão, de toda alienação de si mesmo.

Mas, o que nos parece mais importante aqui, fala-se sempre do "ser do homem". O "Super-homem”, pois, é entendido como realização do homem. Valha a expressão, da realização da "diferença na identidade". Vale isto do homem, mas, em grau ainda maior, daquela realização global que chamamos a história dos homens, a história humana.

Por isso, Jacques Derrida, ao falar da "diferença entre o homem superior e o 'Super-homem'”, exprime-se assim:

"O último - que não é o último homem - acorda e parte, sem se voltar para o que deixa atrás de si. Queima o seu diário e apaga os traços dos seus passos. O seu riso explodirá então em direção a um retorno que não terá mais a forma da repetição metafísica do humanismo, nem também, sem dúvida, 'para além da metafísica', a do memorial ou da guarda do sentido do Ser, a da casa e da verdade do Ser" (DERRIDA, s/d, p. 169).

Assim, o "Super-homem" de Nietzsche é um conceito filosófico ou, melhor dizendo, o conteúdo de uma Antropologia Filosófica produzida sem o perfil clássico do rosto angustiado por qualquer saudade metafísica.

\section{Referências}

CASTRILLO MIRAT, Dolores. Em Prólogo a NIETZSCHE, Friedrich. La Voluntad de Poderio. Madrid: EDAF, 1986.

DERRIDA, Jacques. Margens da Filosofia. Porto: Rés [s.d.].

DUSSEL, Enrique D. Filosofia da Libertação na América Latina. São Paulo: Loyola, 1980.

FERRATER MORA, José. Diccionario de Filosofía 4. Madrid: Alianza Editorial, 1986. 
HEIDEGGER, Martin. Nietzsche II. Paris: Gallimard, 1971.

NIETZSCHE, Friedrich. Assim Falava Zaratustra. São Paulo: Hemus, 1979.

La Voluntad de Poderío. Madrid: EDAF, 1986.

OS PENSADORES. Nietzsche. São Paulo: Abril Cultural, 1983.

PENZO, Giorgio. "História da Influência de Nietzsche na Literatura e na Filosofia até a Interpretação de Heidegger". In: CONCILIUM, n. 165 - 1981/5: Nietzsche e o Cristianismo. Petrópolis: Vozes, 1981

SCHELLER, Max. La idea del hombre y la historia. Buenos Aires: La Pléyade, 1981.

WELTE, Bernhard. “O 'super-homem' de Nietzsche e sua ambígua questionabilidade”. In: CONCILIUM, n. 165 - 1981/5: Nietzsche e o Cristianismo. Petrópolis: Vozes, 1981. 